\title{
Senescence and Type 2 Diabetic Cardiomyopathy: How Young Can You Die of Old Age?
}

\author{
Sian M. Henson ${ }^{1 *}$ and Dunja Aksentijevic ${ }^{2,3 *}$ \\ ${ }^{1}$ Centre for Translational Medicine and Therapeutics, London, United Kingdom, ${ }^{2}$ Centre for Biochemical Pharmacology, London, \\ United Kingdom, ${ }^{3}$ Centre for Inflammation and Therapeutic Innovation William Harvey Research Institute, Barts and The London \\ School of Medicine and Dentistry, Queen Mary University of London, London, United Kingdom
}

\section{OPEN ACCESS}

Edited by:

Andrew J. Murray,

University of Cambridge,

United Kingdom

Reviewed by:

Dongze Qin,

Albert Einstein College of Medicine,

United States

Rajesh Katare,

University of Otago, New Zealand

${ }^{*}$ Correspondence:

Dunja Aksentijevic

d.aksentijevic@qmul.ac.uk

Sian M. Henson

s.henson@qmul.ac.uk

Specialty section:

This article was submitted to Translational Pharmacology,

a section of the journal

Frontiers in Pharmacology

Received: 28 May 2021 Accepted: 16 September 2021

Published: 07 October 2021

Citation:

Henson SM and Aksentijevic D (2021)

Senescence and Type 2 Diabetic Cardiomyopathy: How Young Can You

Die of Old Age?

Front. Pharmacol. 12:716517.

doi: 10.3389/fphar.2021.716517
Inflammation is well understood to be a physiological process of ageing however it also underlies many chronic diseases, including conditions without an obvious pathogenic inflammatory element. Recent findings have unequivocally identified type 2 diabetes (T2D) as a chronic inflammatory disease characterized by inflammation and immune senescence. Immunosenescence is a hallmark of the prolonged low-grade systemic inflammation, in particular associated with metabolic syndrome and can be a cause as well as a consequence of T2D. Diabetes is a risk factor for cardiovascular mortality and remodelling and with particular changes to myocardial structure, function, metabolism and energetics collectively resulting in diabetic cardiomyopathy. Both cardiomyocytes and immune cells undergo metabolic remodelling in T2D and as a result become trapped in a vicious cycle of lost metabolic flexibility, thus losing their key adaptive mechanisms to dynamic changes in $\mathrm{O}_{2}$ and nutrient availability. Immunosenescence driven by metabolic stress may be both the cause and key contributing factor to cardiac dysfunction in diabetic cardiomyopathy by inducing metabolic perturbations that can lead to impaired energetics, a strong predictor of cardiac mortality. Here we review our current understanding of the cross-talk between inflammaging and cardiomyocytes in T2D cardiomyopathy. We discuss potential mechanisms of metabolic convergence between cell types which, we hypothesize, might tip the balance between resolution of the inflammation versus adverse cardiac metabolic remodelling in T2D cardiomyopathy. A better understanding of the multiple biological paradigms leading to T2D cardiomyopathy including the immunosenescence associated with inflammaging will provide a powerful target for successful therapeutic interventions.

Keywords: type 2 diabetes, immunosenescence, diabetic cardiomyopathy, inflammaging, cardiac metabolism

\section{INTRODUCTION}

Type 2 diabetes (T2D) is an enormous global medical and economic burden and its prevalence is on the rise with an ever ageing, increasingly obese population. It is a debilitating, chronic disease affecting almost half a billion people worldwide (World Health Organisation, 2021). Once a "privilege" of high-income Western societies, prevalence of T2D has been rapidly rising in lowand middle-income countries (World Health Organisation, 2021; Miranda et al., 2019). In 2016, an estimated 1.6 million deaths were directly caused by diabetes with an additional 2.2 million deaths 
attributable to hyperglycaemia in 2012 (World Health Organisation, 2021). Therefore, T2D is an increasing risk to human life span. The current COVID-19 pandemic has added to this chronic metabolic disease burden as the patients with underlying obesity and T2D faced significantly poorer prognosis and clinical outcomes (Barron et al., 2020; Dennis et al., 2021). Therefore, there is a definitive, rapidly increasing necessity for improved understanding of fundamental cellular mechanisms in T2D which can, in turn, help the development of improved treatments and innovative diagnostic techniques. T2D is often presented as a multimorbid disease cluster as it is a major risk factor for the premature onset of multiple age-related conditions such as chronic kidney disease, stroke, impaired wound healing, infection, depression, cognitive decline and inflammation (Kannel and McGee, 1979a; Anderson et al., 2001; Beckman et al., 2002; Brem and Tomic-Canic, 2007). T2D is especially a high-risk factor for cardiovascular mortality and cardiac remodelling, with coronary vessel disease and atherosclerosis being primary reasons for the increased incidence of cardiovascular dysfunction (Wilson, 2001; An and Rodrigues, 2006). Nevertheless, a predisposition to heart failure might also reflect the effects of underlying abnormalities in diastolic function that can be detected in asymptomatic patients with diabetes alone (Fein, 1990; Bertoni et al., 2003; Diamant et al., 2003; Emerging Risk Factors et al., 2010). These observations suggest that progression of T2D leads to specific changes to myocardial structure, function, metabolism and energetics collectively termed diabetic cardiomyopathy ( $\mathrm{dbCM}$ ) (An and Rodrigues, 2006).

$\mathrm{T} 2 \mathrm{D}$ is more common in an ageing host and "accelerated ageing" has been proposed as a pathogenic mechanism, including cell ageing leading to a complex phenotype termed senescence (Hughes et al., 2020). Over the past 30 years, cellular senescence has been identified as a possible trigger of general tissue dysfunction and ageing phenotypes (Muñoz-Espín and Serrano, 2014; Dookun et al., 2020). Senescent cell load is low in young individuals but increases with ageing. It is evolutionarily conserved amongst species and is a paradigm of "antagonistic pleiotropy", an evolutionary hypothesis postulating that traits which are considered beneficial to the organism's health in early life can exhibit detrimental effects at later stages due to a drop in natural selection pressure (Williams, 1957). Therefore, it can have both detrimental and positive effects dependant on the physiological context. For example, senescence has beneficial effects in the context of wound healing (Demaria et al., 2014), embryonic development (Muñoz-Espín et al., 2013; Storer et al., 2013) and tissue repair; however, when senescent cells accumulate they contribute to tissue dysfunction in the context of ageing and related pathologies (Gorgoulis et al., 2019). Several studies have shown that senescence accumulates in multiple cardiovascular cell populations and is linked with cardiovascular diseases (CVD) including heart failure (HF) (Olivieri et al., 2013; Childs et al., 2017). Furthermore, there are an increasing number of interventional trials in cardiovascular disease and T2D targeting ageing, inflammation and cellular phenotype (Table 1).
In $\mathrm{T} 2 \mathrm{D}$, comorbidities including obesity, hypertension and atherosclerosis all have the ability to increase the number of senescent cells (Minamino and Komuro, 2007; Westhoff et al., 2008; Minamino et al., 2009; Tchkonia et al., 2010). However, the relationship between $\mathrm{T} 2 \mathrm{D}$ and myocardial senescence may be both complex and complementary. The microenvironment of systemic metabolic stress in T2D could be permissive to the development and accumulation of senescent cells. On the other hand, senescent cells may contribute to the cardiac parenchyma dysfunction and comorbidities observed in T2D. Overall, it is likely that these complex interactions might lead to a malicious positive feedback in which systemic metabolic dysfunction in the early stages of T2D leads to immune cell senescence that in turn contributes to the worsening of cardiac function and tissue metabolism, which further increases the formation of senescent cells while decreasing their removal (Palmer et al., 2019).

The aim of this review is to spark discussion and help generate hypotheses that may link senescence to cardiometabolic complications in T2D. We hypothesize that clearing senescent pro-inflammatory immune cells or targeting the SASP (Senescence-Associated Secreting Phenotype) may present opportunities for the development of revolutionary therapies for diabetic cardiomyopathy and its complications, leading to advances in its treatment and prevention. Furthermore, we review our current understanding of the metabolic remodelling of both heart tissue and senescent immune cells in T2D, and we discuss potentially fundamental mechanisms by which these metabolic responses influence and intersect each other to ultimately determine the prognosis of the myocardial inflammation.

\section{PATHOPHYSIOLOGY OF TYPE 2 DIABETES}

In terms of its clinical manifestation, T2D is heterogenous disease. However, there are two primary pathological mechanisms responsible for the development of T2D: defective insulin production by pancreatic $\beta$-cells and insulin resistance (IR) which arises due to the impaired ability of insulin-sensitive tissues to respond to insulin. Multiple organs are involved in the aetiology of type 2 diabetes: pancreas ( $\beta$-cells, $\alpha$-cells), liver, skeletal muscle, kidneys, brain, small intestine, and adipose tissue (Defronzo, 2009). Emerging data also suggests an important pathophysiological role of inflammation, adipokine dysregulation, abnormal gut microbiota and immune dysregulation in the development of T2D (Figure 1) (Schwartz et al., 2016). Traditionally, loss of $\beta$-cells by cell death has been considered the key cause of $\beta$-cell dysfunction in T2D. However, multiple studies have identified $\beta$-cell damage caused by lipotoxicity and glucotoxicity-driven endoplasmic reticulum (ER) stress rather than cell loss to be the main cause of impaired insulin secretion (Galicia-Garcia et al., 2020).

IR refers to a decreased response of insulin-sensitive cells to insulin and an impaired response to circulating insulin by blood glucose levels (Czech, 2017). IR can be defined by three broad categories: reduced insulin secretion by $\beta$-cells; insulin antagonists in the plasma and impaired insulin tissue response 
TABLE 1 | Examples of interventional trials in cardiovascular disease and T2D targeting ageing, inflammation and cellular phenotype [table adapted from (Hughes et al., 2020)]. Study name

Study

Study overview

Disease

area

\section{Ageing}

Cardiovascular protective effects of wolfberry in middle-aged and older adults

Regulation of endothelial progenitor cells by short-term exercise (EPC-Ex)

Prevention of cardiovascular stiffening with aging and hypertensive heart disease (LVH)

n-3 PUFA for vascular cognitive aging

Impact of ageing on adipose, muscle and systemic inflammation

Cell signaling and resistance to oxidative stress: effects of aging and exercise

NCT03535844

NCT01169831

NCT03476785

NCT01953705

NCT02777138

NCT03419988

Resistance exercise and low-intensity physical activity breaks in sedentary time to NCT03771417 improve muscle and cardiometabolic health (REALPA)

Dietary reduction of AGEs to prevent cognitive decline in elderly diabetics

Inflammation

AZD1656 in diabetic patients hospitalised with suspected or confirmed COVID-19 NCT04516759 (ARCADIA)

Effect of IL-1 $\beta$ inhibition on inflammation and cardiovascular risk

NCT02272946

ASSessing the effect of Anti-LL-6 treatment in myocardial infarction: the ASSAIL-MI NCT03004703 trial (ASSAIL-MI)

Effects of SGLT-2 inhibition on myocardial fibrosis and inflammation as assessed by NCT03782259 cardiac MRI in patients with DM2

\section{Cellular processes}

Early iNO for oxidative stress, vascular tone and inflammation in babies with hypoxic NCT01891500 respiratory failure

Impacts of mitochondrial-targeted antioxidant on peripheral artery disease patients

Effects of saxagliptin on adipose tissue inflammation in humans

NCT03506633

NCT02285985
An investigation into the protective effects of Wolfberry to change endothelial function CVD

and lipidomic profiles in a single-blind 16-weeks study

The effect of exercise on endothelial progenitor cell numbers in inactive older adults and CVD endurance athletes via an open interventional study

An exercise intervention to prevent the age-related stiffening of the left ventricule and CVD vasculature using an open interventional trial

An investigation into the effects of omega 3 PUFA to support small blood vessels in the CVD

brain and brain health in adults $>75$ years of age at a risk of cognitive decline via an

interventional study

Observational study of immune cells and inflammatory markers in adipose tissue $\quad$ CVD, T2D between younger and older males with equivalent lifestyles

An investigation of the effects of exercise on the expression of nuclear erythroid-2-p45- CVD, T2D N/A related factor-2 (Nrf2) in peripheral blood mononuclear cells in healthy younger

(18-28 years) and older (>60 years) adults using an open interventional study

The impact of resistance exercise with low-intensity physical activity on skeletal muscle CVD, T2D N/A

and cardiometabolic health in adults aged between 65 and 80 years using an

interventional study

An assessment of feasibility to reduce dietary AGEs and cognitive decline using an T2D

intervention pilot study

Assessment of the safety and efficacy of a glucokinase activator (AZD1656) in patients T2D

with either Type 1 or Type 2 diabetes, hospitalised with COVID-19. A randomised

double-blind, placebo-controlled clinical trial

Investigate into the effects of inhibiting IL-1 $\beta$ using canakinumab to limit vascular $\quad$ CVD

inflammation in HIV-infected individuals via an interventional study

Assessing the impact of a single dose of an anti-IL-6 antibody (tocilizumab) to treat CVD

myocardial damage following myocardial infarction, an interventional study

Inhibition of the glucose transporter, SGLT-2, using dapagliflozin and its impact on CVD, T2D cardiovascular health and inflammation in patients with T2D, an interventional study

N/A

N/A

$\mathrm{N} / \mathrm{A}$

$\mathrm{N} / \mathrm{A}$

$\mathrm{N} / \mathrm{A}$

An investigation of inhaled nitric oxide in hypoxic newborns with respiratory failure to CVD reduce biomarkers of oxidative injury via an interventional study

The impact of targeted mitochondrial antioxidant (MitoQ) usage on vascular endothelial CVD

function in patients with peripheral vascular disease using an interventional study

An investigation of saxagliptin on adipose tissue inflammation in obese volunteers, an T2D interventional study

Phase

(1)




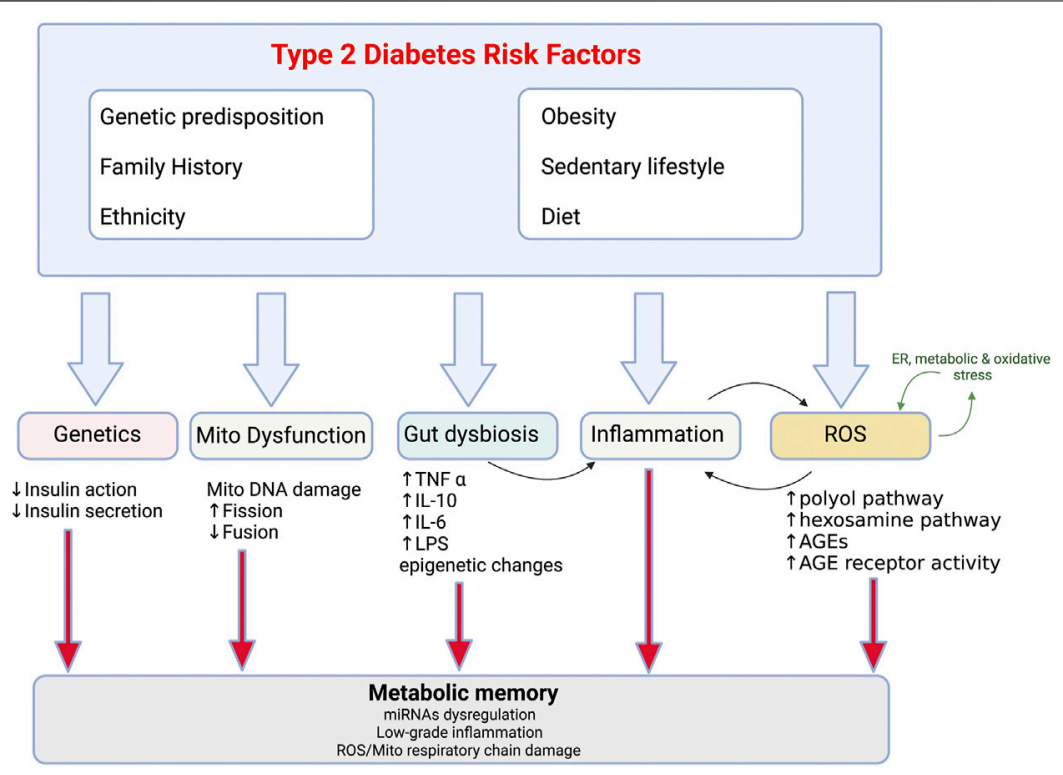

FIGURE 1 | Risk factors and pathophysiological changes in type 2 diabetes Combination of the modifiable (obesity, sedentary lifestyle, diet) and non-modifiable (genetics, ethnicity, family history) risk factors and resultant pathological changes which drive reduction in insulin sensitivity in T2D. Mito-mitochondria, AGE-advanced glycated end products, ROS- reactive oxygen species.

in target tissues (Pearson et al., 2016). The action of insulin is also affected by the interplay of additional molecules such as IGF-1 and growth hormone. IR contributes to increased hepatic glucose production and reduced glucose uptake by muscles, liver and adipose tissue. A diminished insulin action in these target tissues often precedes the development of systemic IR. T2D patients are commonly characterized by obesity [body-mass index (BMI) $\geq 30 \mathrm{~kg} / \mathrm{m}^{2}$ ] and higher body fat percentage especially in the abdominal region.

Obesity is the strongest risk factor for the development of T2D and accompanies metabolic perturbations resulting in IR (Carey et al., 1997; Sinha et al., 2002). It promotes IR through multiple inflammatory mechanisms including adipokine dysregulation and increased release of fatty acids (FA) into circulation. Even if both processes relating to disrupted glucose homeostasis take place early in the pathogenesis of T2D, $\beta$-cell dysfunction is considered a more severe cause of T2D than IR. However, concomitant IR and $\beta$-cell dysfunction amplify hyperglycaemia leading to worsening of T2D (Cerf, 2013). In addition to the disruption in insulin production, there are a series of pathological conditions which perpetuate T2D including gut dysbiosis, metabolic memory and mitochondrial dysfunction (Figure 1) (reviewed in (Galicia-Garcia et al., 2020)). Furthermore, development of T2D is also affected by the genetics and the environment (Figure 1). Genome-wide association studies have identified the polygenic nature of T2D, as well as identified some of the common glycaemic genetic variants for T2D. These account for $10 \%$ of total trait variance highlighting their importance (Grarup et al., 2014). In addition, ethnic origin may lead to different phenotypes that increase predisposition to risk factors such as hypertension, IR and dyslipidaemia (Wong et al., 2016). Genetic factors are exacerbated by the exposure to an environment characterized by obesity and physical inactivity including a high-calorie, Western diet.

\section{DIABETIC CARDIOMYOPATHY}

Accelerated heart failure (HF) is a common manifestation of cardiovascular disease in T2D (Shah et al., 2015). Approximately $£ 3$ billion of the $£ 10$ billion total cost of diabetes to the UK National Health Service (NHS) is associated with the cardiovascular complications of diabetes, and in the next 20 years this figure is projected to double (Hex et al., 2012). The Framingham Heart Study concluded that T2D independently increases the HF risk up to 2-fold in men and 5-fold in women compared to matched controls (Kannel et al., 1974; Kannel and McGee, 1979b). Furthermore, adjusting for other risk factors including age, hypertension, hypercholesterolemia, and coronary artery disease does not eliminate increased HF incidence. 40 years ago, the term "diabetic cardiomyopathy" $(\mathrm{dbCM})$ was defined to initially define ventricular dysfunction in the absence of hypertension and coronary artery disease in T2D patients (Kenny and Abel, 2019). However, over the years it has been identified that the progression of T2D leads to specific changes to myocardial structure, function, metabolism and energetics, collectively termed diabetic cardiomyopathy ( $\mathrm{dbCM}$ ) (An and Rodrigues, 2006). Thus, the use of the term "diabetic cardiomyopathy" has been extended to describe the increased susceptibility of the T2D heart to dysfunction. The mechanisms by which $\mathrm{T} 2 \mathrm{D}$ leads to $\mathrm{dbCM}$ have been extensively reviewed elsewhere (Kenny and Abel, 2019; Marelli-Berg and Aksentijevic, 2019; Tan et al., 2020). However, the principal pathways that 


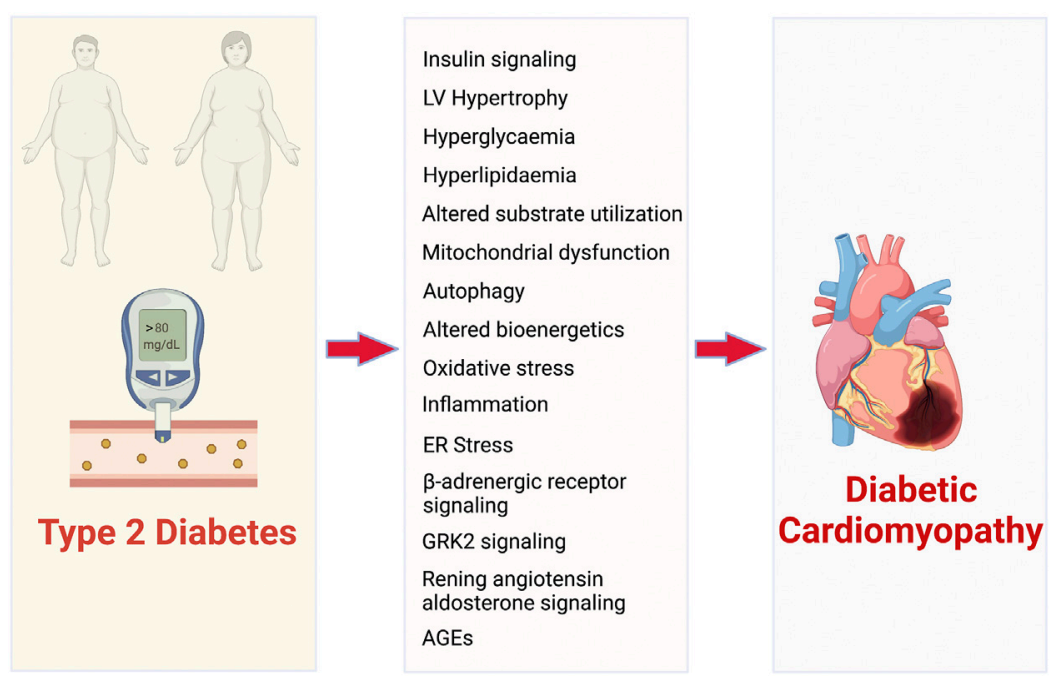

FIGURE 2 | Pathophysiological mechanisms that contribute to the development of diabetic cardiomyopathy and associated heart failure. AGEs- advanced glycated end products.

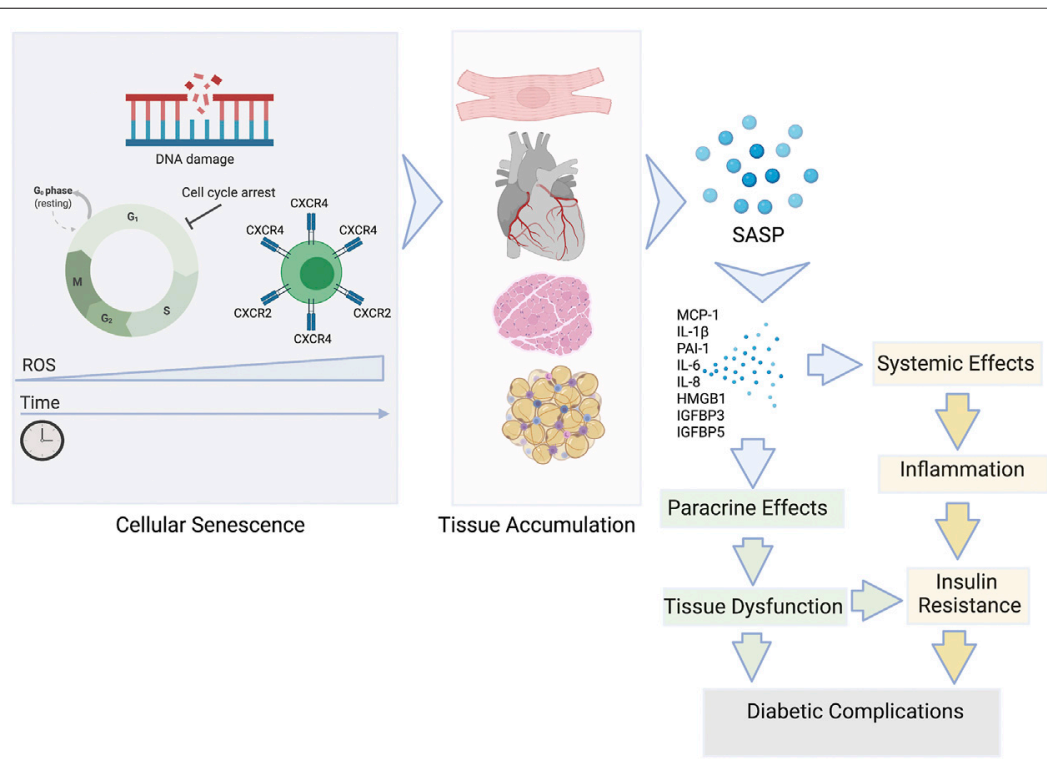

FIGURE 3 | The role of senescent cells in the development of insulin resistance and T2D complications. Senescent cells accumulate in tissues during ageing and the development of pathophysiological states. The SASP is a diverse group of proinflammatory mediators: cytokines, chemokines, growth factors released by the senescent cells systemically and locally. The SASP can affect the function of surrounding cells via paracrine signalling contributing to tissue dysfunction and ultimately damage that can cause diabetic complications. SASP factors can also enter the circulation and add to the chronic inflammatory state commonly associated with the insulin resistance development.

contribute to the development of $\mathrm{dbCM}$ and diabetes-associated HF have been summarised in Figure 2.

\section{TYPE 2 DIABETIC ENVIRONMENT PROMOTES SENESCENCE}

Cellular senescence is thought to have originated as the antitumour mechanism in response to oncogenic activation and by definition includes irreversible growth arrest in response to cellular stresses such as DNA damage, oxidative stress and telomere erosion (Figure 3). Despite the inability to divide, senescent cells maintain high metabolic activity supporting the secretion of growth factors, proinflammatory cytokines, chemokines, angiogenetic factors, and matrix metalloproteinases collectively defined as the SenescenceAssociated Secreting Phenotype or SASP (Coppé et al., 2008; Kuilman and Peeper, 2009). 
Production of the SASP empowers even a small number of senescent cells present in any organ (ie $<20 \%$ ) to exert significant, widespread systemic effects (Campisi and d'Adda di Fagagna, 2007). Senescent cells also have the ability to initiate a damaging positive feedback mechanism by promoting the spread of senescence to neighbouring cells (Zhu et al., 2014; Tchkonia et al., 2013; Nelson et al., 2012). This potentially includes obesity-related senescence promoting chronic, low-grade sterile inflammation. Driven by the primary hallmarks of ageing, there is low-grade inflammation in older individuals which is similar to the systemic inflammation seen in chronic disease, a phenomenon termed "inflammaging" (Franceschi and Campisi, 2014). This may be the crucial link between underlying obesity and chronic inflammation leading to cardiac metabolic dysfunction in T2D (Figure 3). SASP mediators have also been shown to reduce peripheral insulin sensitivity, enhance chemoattraction and activate pro-inflammatory macrophages, that further contribute to IR (Palmer et al., 2019). Analogous to the other age-related chronic diseases, T2D may be caused in part by a convergence of the basic ageing mechanisms that underlie agerelated tissue dysfunction, including macromolecular damage, chronic sterile inflammation, progenitor cell dysfunction, and cellular senescence (López-Otín et al., 2013). However, the full impact on the cardiac function and metabolism are yet to be fully understood.

\section{PANCREATIC DYSFUNCTION}

Pancreatic dysfunction and the resultant impairment in insulin response and hyperglycaemia are the hallmarks of T2D. Several studies have shown that the gene expression in $\beta$ cells changes with ageing including increased expression of the genes related to cellular senescence, such as $C d k n 2 a$ and Cdkn2b (Helman et al., 2016). Deletion of senescent $\beta$ cells, via senolysis in a pre-clinical diabetic model was found to preserve insulin secretory capacity, providing a link between cellular senescence and severe dysregulation of insulin secretion (Thompson et al., 2019). Furthermore, high-fat diet experimental models have confirmed pancreatic $\beta$ cell senescence as a key contributor to T2D (Sone and Kagawa, 2005). In transgenic models of T2D, the cell cycle inhibitor p27 (a marker of senescence) increases in pancreatic $\beta$ cells, and p27 deletion increased insulin secretion and islet mass through increased proliferation (Uchida et al., 2005). In transgenic mice lacking p53-dependent apoptosis, the number of senescent cells rapidly increases and is associated with dysfunction of pancreatic $\beta$ cells, causing an overt diabetic phenotype (Tavana et al., 2010). This represents an accelerated model of agerelated T2D and is consistent with the hypothesis that cellular senescence could result in decreased insulin synthesis and release. Therefore, eliminating senescent cells by senolytic drug agents may possibly prevent b cell dysfunction (Zhu et al., 2015).

\section{SYSTEMIC METABOLIC STRESS}

Hyperglycaemia is a hallmark of T2D and has been shown to drive premature senescence in endothelial cells, renal mesangial cells, adipose-derived stem cells and fibroblasts (Yokoi et al.,
2006; Blazer et al., 2002; Ksiazek et al., 2008; Cramer et al., 2010). Whilst the mechanism of hyperglycaemia-induced senescence remains to be understood, potential mechanisms include mitochondrial dysfunction and increased reactive oxygen species (ROS) damage (Ksiazek et al., 2008). High glucose can also enhance the formation of advanced glycation end products (AGEs) (Palmer et al., 2019). Increased AGE signalling through their receptors (RAGE), of which the SASP factor HMGB1 is also the agonistic ligand (Figure 3), has been shown to cause premature senescence in renal tubular cells (Liu et al., 2014; Palmer et al., 2019).

In addition to hyperglycaemia, systemic dyslipidaemia and the resultant lipotoxicity play an important role in the pathophysiology of diabetic cardiomyopathy. Increased intracellular ceramide concentration has been linked to promotion of senescence due to alterations in fatty acid metabolism in response to environmental stress via p53 and p38 mediated pathways (Ford, 2010). Synthesis of ceramides is increased in T2D causing systemic tissue damage including apoptosis of pancreatic $\beta$ cells (Galadari et al., 2013). In fibroblasts and endothelial cells, ceramide exposure increases the expression of senescence markers thus driving the process of cellular senescence (Ford, 2010). Moreover, inhibition of de novo ceramide synthesis in ob/ob transgenic mice has been shown to reduce the SASP factors PAI-1 and MCP-1 as well as improve insulin and glucose sensitivity (Yang et al., 2009). Furthermore, conversion of the T2D biomarker 1-deoxysphinganine to its ceramide metabolite 1-deoxy-dihydroceramide, decreases insulin secretion in Ins-1 $\beta$ cells and primary islets and triggers p21-dependent cellular senescence in Ins-1 cells (Zuellig et al., 2014).

\section{IGF-1/GROWTH HORMONE}

Whilst the relationship between growth hormone, insulin resistance and T2D is complex and still not fully explored, there have been a series of studies suggesting this complex axis plays an important role in triggering senescence. Alterations in the secretion and tissue response to growth hormones in T2D have been implicated in promoting senescence. Components of this pathway such as growth hormone, IGF1 and IGF5 binding protein (IGFBP5) have all been shown to trigger senescence (Kim et al., 2007; Stout et al., 2014; Tran et al., 2014). In addition, IGFBP3, has been implicated in the SASP response, playing a role in the paracrine propagation of senescence to surrounding cells and tissues (Elzi et al., 2012). Indeed, a comprehensive proteomic database of soluble proteins and exosomal cargo SASP factors originating from multiple senescence inducers and cell types has been published (Basisty et al., 2020). A core SASP exists of mediators that are secreted irrespective of the senescent stimuli or cell type investigated, which included IGFBPs. Chronic exposure to IGF-1 in T2D due to hyperinsulinaemia and altered IGFBP levels and can lead to p53-mediated premature senescence (Palmer et al., 2015). Consistent with the role of IGF-1 in senescence, the activity of Akt which is a major downstream target of the insulin/IGF-1 
signalling pathway, is increased in senescent cells. Furthermore, in vitro endothelial cell experiments have shown that Akt inhibition both delays senescence and increases replicative cellular lifespan (Palmer et al., 2015). IGFBP members IGFBP5 and IGFB3, were shown to increase during endothelial and fibroblast senescence. IGFBP5 may induce cellular senescence on its own via a p53-dependent, p16-independent pathways (Palmer et al., 2015) and the levels of IGFBP3 can be modulated by the SASP component PAI-1 (Palmer et al., 2015). IGFBP3 was shown to trigger insulin resistance independently of IGF binding, supported by decreased GLUT4 translocation to the plasma membrane as well as reduced Akt phosphorylation in response to insulin (Palmer et al., 2015). In addition, overexpression of IGFBP3 led to decreased glucose tolerance, insulin resistance, and hyperglycemia (Palmer et al., 2015).

\section{CARDIOMYOCYTE SENESCENCE}

Defining senescence in classic terms in cardiomyocytes is a challenge as they are terminally differentiated cells, necessitating multiple methodologies such as senescenceassociated- $\beta$-galactosidase (SA- $\beta$-gal) staining, quantification of p53, p21 and p16 together with an assessment of the SASP. It should be noted that cellular senescence is a separate process to apoptosis having distinct biological pathways (Childs et al., 2014). Soon after birth, cardiomyocytes undergo cell cycle arrest due to the activation of the DNA damage response introduced through exposure to higher concentration of oxygen in the postnatal environment (Shimizu and Minamino, 2019). Therefore, cell cycle arrest alone cannot be used to define senescence. Instead, the definition of cardiomyocyte senescence includes DNA damage response, ER stress, mitochondria dysfunction, contractile dysfunction, hypertrophic growth, SASP and $\beta$-galactosidase expression (Ock et al., 2016; Hernandez-Segura et al., 2018; Tang et al., 2020). Cardiomyocyte senescence is regulated by the intracellular signalling pathways such as the metabolic sensors/regulators and the extracellular microenvironment, including the paracrine effects of the nonmyocytes such as endothelial cells, fibroblasts and immune cells. DNA damage is both an important driver and a hallmark of cardiomyocyte senescence, with telomere shortening being the most common DNA damage feature of senescent cells (Shay and Wright, 2019). Evidence from both animal and human studies has shown that post-mitotic cardiomyocyte senescence is mediated by length-independent telomere damage (Ball and Levine, 2005; Anderson et al., 2019). Administration of cytotoxic agents such as doxorubicin were shown to upregulate p16 ${ }^{\text {Ink4a }}$, p21 and SA- $\beta$-gal level (Shirakawa et al., 2016). For example, in the human failing heart, hypertrophic cardiomyopathy (HCM) HfrEF and ischemic cardiomyopathy cardiomyocyte telomeres were shorter compared to healthy controls (Shakeri et al., 2018). DNA damage is also closely linked to alterations in cardiac mitochondrial function as in senescent cardiomyocytes, mitochondrial ROS production and accumulation induces DNA damage and repair response (Tang et al., 2020). A recent study has offered interesting and novel mechanistic insight into how senescence can accumulate in a predominately post-mitotic cardiomyocyte population (Dookun et al., 2020).

It has been shown that accumulation of persistent telomereassociated foci of DNA damage (TAF) is a major driver of cardiomyocyte senescence during ageing. Cardiomyocyte TAF were induced by oxidative stress, as a result of age acquired mitochondrial dysfunction, and occured independently of telomere length and cell cycle activity. Furthermore, DNA damage-induced PARP1 activation contributes to the cardiac contractile dysfunction via NAD metabolite depletion (Zhang et al., 2019). Regardless of the stressors triggering the response, DNA damage at telomere regions leads to the activation of a persistent DNA damage response (DDR), due to the inability of telomere regions to undergo non-homologous end joining (Fumagalli et al., 2012; Dookun et al., 2020). This permanent DDR results in the activation of either one or both $\mathrm{p} 53 / \mathrm{p} 21^{\text {Cip }}$ or

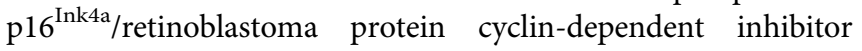
pathways (Dookun et al., 2020). Regardless of the source of damage, senescent cardiomyocytes are characterized by SASP production. This includes CCN family member 1 (CCN1), interleukins (IL1 $\alpha$, IL1 $\beta$, and IL6), tumour necrosis factoralpha (TNFa), and monocyte chemoattractant protein-1 (MCP1), endothelin 3 (Edn3), tumour growth factor-beta (TGF $\beta$ ), and growth and differentiation factor 15 (GDF15) (Dookun et al., 2020). These SASP factors are crucial regulators of non-myocytes within the local microenvironment and contribute to cardiac remodelling and dysfunction in senescent states such as T2D.

One of the key features of the senescent murine and human myocardium is the hypertrophic cardiomyocyte enlargement and increased pro-hypertrophic gene expression (Cui et al., 2018). Furthermore, activation of the inhibitory components of cell cycle regulators have been shown to ameliorate cardiac hypertrophy (Maejima et al., 2008).

\section{CELLULAR SENESCENCE AND CARDIAC METABOLIC DYSFUNCTION IN TYPE 2 DIABETES}

Senescent cell burden increases in ageing and obesity and may play a role in causing or exacerbating myocardial dysfunction in T2D. There have been a number of studies over the years detailing extensive changes in cardiac metabolism during senescence and T2D, however the metabolic nexus between these comorbidities have not been identified. Decades of cardiac ageing research have helped to understand the alterations in cardiac metabolism associated with the senescence. Both pathological states are characterized by remodelling at the cellular level in the form of left ventricular hypertrophy, development of contractile dysfunction and maladaptive changes in cardiac metabolic profile. It has been shown that senolysis in obese mice led to improved cardiac diastolic function, with important translational implications for T2D cardiomyopathy patients, in whom heart failure with preserved ejection fraction is common (Palmer et al., 
2019). Furthermore, as an overarching comorbidity there is a presence of inflammation both in terms of inflammageing of the immune system cells as well as a chronic low-grade inflammation of cardiac parenchyma. However, despite the known link between senescence, inflammation and T2D, the exact relationship between these morbidities has not been established.

The adult heart has an enormous ATP demand in order to support its continuous contractile work as well as in order to deal with the dynamic workload alterations. Continuous supply of ATP for the healthy adult heart is provided by mitochondrial oxidative phosphorylation (90\% of ATP synthesis). In cardiac mitochondria, fatty acids and carbohydrates are the main substrates for ATP synthesis via oxidative phosphorylation (OXPHOS). Under physiological conditions fatty acid oxidation (FAO) accounts for approximately $70 \%$, whilst the remaining contribution is from oxidation of carbohydrates via pyruvate and lactate. Substrate usage by the heart is flexible, as the substrate utilisation ratio is rapidly adjusted in order to maintain a continuous ATP supply (reviewed in (Lopaschuk et al., 2021)). Severe metabolic alterations characterise the diabetic heart, with changes in substrate utilization, alterations in mitochondrial organisation and function, together with enhanced ROS production all being observed and which collectively lead to energetic deficit (reviewed in (Marelli-Berg and Aksentijevic, 2019)).

Due to underlying insulin resistance, myocardial glucose utilization is compromised, accompanied by increase in FA supply. As a result, cardiac ATP synthesis switches to the dependence on FA utilization. High FA uptake and metabolism not only augment accumulation of FA intermediates and triglycerides but also increase oxygen utilization and generation of reactive oxygen species (ROS) causing cardiomyocyte damage (reviewed in (Marelli-Berg and Aksentijevic, 2019)) However, how these metabolic alterations contribute to the senescence of cardiomyocytes in dbCM or whether cardiomyocyte senescence in this scenario, is the primum movens of cardiac cells metabolic dysfunction remains unknown. Intermittent hyperglycaemia can induce stress senescence via p21 and p16 but sustained hyperglycaemia was found to activated telomerase and shorten telomere length, indicative of replicative senescence (Maeda et al., 2015). There have however been suggestions that altered mitochondrial metabolism may be the pivotal contributor to myocardial senescence thus forming the basis for the increased sensitivity of the T2D heart to stress and functional decline (Lesnefsky et al., 2016). The age-associated senescent cardiomyocyte is characterized by metabolic inflexibility, with a decreased FAO and enhanced dependence on glucose metabolism via enhanced PDK4 content (Hyyti et al., 2010; Chiao et al., 2016). Senescence impairs mitochondrial OXPHOS, including decreased activity of mitochondrial complexes III and IV, which account for the decrease in ATP synthesis (Lesnefsky et al., 2016). Furthermore, ageing decreases mitochondrial content, altered fission, fusion, autophagy among the myofibrils resulting in $\approx 50 \%$ decrease in mitochondrial function, impacting all metabolic substrates (Cramer et al., 2010). The presence of defective mitochondria leads to enhanced production of oxidants leading to oxidative injury and the triggering of oxidant signalling for cell death. Thus, hypothetically triggering of senescence by systemic metabolic stress as well as pro-inflammatory cell accumulation during the development of diabetic cardiomyopathy may exacerbate any underlying cardiac metabolic derangement due to altered insulin sensitivity.

ROS-mediated mitochondrial DNA damage and mutations are thought to be a major cause of reduced mitochondrial biogenesis in senescent and diabetic hearts. Mitochondrial polymerase mutation increases oxidative stress in middle-aged mice resulting in cardiomyopathic changes (Tchkonia et al., 2010; Dookun et al., 2020). Threshold for ROS-induced ROS-release is reduced in the aged cardiomyocytes making them more sensitive to mitochondrial permeability transition pore (mPTP) induction. mPTP opening results in mitochondrial swelling leading to impaired ATP provision, apoptosis and oxidative stress. Mitochondria isolated from variety of aged and senescent tissue have suggested that aging affects the opening of mPTP (Panel et al., 2018). Mechanistically, mPTP opening is prevented in mitochondria from young and healthy animals by the high membrane potential $(\Delta \Psi)$, tightly regulated matrix $\mathrm{Ca}$ concentration and ROS scavenging [reviewed in (Panel et al., 2018)]. With ageing there is a progressive loss of mitochondrial cristae due to disassembly of ATP synthase dimers, increase in Ca and production of ROS as well as decline in $\Delta \Psi$. Impaired Ca regulation leads to matrix $\mathrm{Ca}$ elevation which is the principal trigger for mPTP opening. Mitochondrial respiratory chain as well as being the main source is also a target of ROS damage. ROS targets multiple sites in mitochondria including respiratory chain complexes leading to enhanced ROS generation and lowering $\Delta \Psi$. Furthermore, enhanced ROS production causes cardiolipin peroxidation which sensitizes $\mathrm{mPTP}$ to $\mathrm{Ca}$ overload (Panel et al., 2018). The theory of increased mPTP opening in senescent rat heart is also supported by failure of pharmacological mPTP inhibitors to produce effects under baseline or stress conditions. Furthermore, in aged mitochondria cyclosporin A (CsA) is unable to inhibit carboxyatractyloside-induced permeability transition and GSK$3 \beta$ inhibition of SB-216763 in ischemic injury is abrogated (García et al., 2009; Zhu et al., 2011; Li et al., 2013). Collectively, these data are consistent with increased susceptibility to apoptosis and suggest that $\mathrm{mPTP}$ is activated in senescent states (Chabi et al., 2008).

Mitochondrial-specific overexpression of catalase in mice leads to the rescue of premature ageing and senescent cardiac phenotype. This observation supports the premise that mitochondrial ROS production and DNA damage are contributors of a vicious circle of ROS-induced ROS- release, resulting in cardiac dysfunction. Further validation of the role of mitochondria in cardiac senescence was derived from the work in a p66shc transgenic mouse.

p66shc is a mitochondrial redox enzyme that forms ROS using electrons leading to $\mathrm{H}_{2} \mathrm{O}_{2}$ production (Soto-Gamez et al., 2019).

The p66shc mutation decreased oxidative damage in mice thus increasing the lifespan and decreasing cardiac dysfunction (Dookun et al., 2020). Therefore, along with diabetes, senescence-induced oxidative stress could exacerbate the vicious cycle of mitochondrial deterioration. 


\section{INFLAMMATORY SIGNALLING AND METABOLIC DERANGEMENT IN DIABETIC CARDIOMYOPATHY}

Numerous cellular mechanisms may be involved in the development of myocardial inflammation in T2D. Mechanisms are mainly directed towards the activation of the NF-kB pathway. This mechanism is prevalent in diabetic vasculature and myocardium contributing to damage by upregulation of cytokines (TGF- $\beta 1$, IL-1 $1 \beta$, IL-6, IL-18, TNF- $\alpha$ ), chemokines and adhesion molecules (Baker et al., 2011; Gordon et al., 2011; Shah and Brownlee, 2016; MarelliBerg and Aksentijevic, 2019). Furthermore, cardiomyocyte-specific overexpression of IкB- $\alpha$ protein, suppressor of the canonical NF- $\mathrm{kB}$ signalling pathway, prevented streptozotocin-induced diabetic cardiomyopathy by inhibiting the renin-angiotensin system (Thomas et al., 2014). Moreover, pharmacological inhibition of NF- $\mathrm{KB}$ in T2D has been shown to reduce mitochondrial abnormalities and reduce myocardial oxidative stress (Mariappan et al., 2010). Chronic low-grade myocardial inflammation driven by metabolic stress may also cause cardiac dysfunction by triggering metabolic perturbations that impair energetics.

For example, cardiac glucose utilization was impaired by IL- 6 administration via SOCS3-dependent inhibition of IRS-1 (Frati et al., 2017). In contrast, IL-6 gene mutation reduced inflammation and rescued glucose metabolism defects triggered by high-fat diet, accompanied by SOCS3 inhibition and IRS-1 reactivation (Ko et al., 2009). Moreover, myocardial PGC-1 $\alpha$ expression, a principal regulator of mitochondrial biogenesis and function (Shah and Brownlee, 2016), has been inhibited by a chronic inflammation via NF-kB activation (Palomer et al., 2009). This may be caused by binding and sequestering of PGC-1 $\alpha$ by p65, thereby resulting in downregulation and inhibition (Alvarez-Guardia et al., 2010). Systemic metabolic derangements in T2D has also been shown to activate NF-kB: hyperglycaemia-triggered activation of the PKC pathway via DAG, increased hexosamine pathway flux, increased AGEs, and increased polyol pathway flux (Du et al., 2003). Common feature of all outlined pathways is increased ROS production and activated nuclear poly-(ADP-ribose)-polymerase (PARP) (Du et al., 2003). PARP over-activation in hyperglycaemia drives $\mathrm{NAD}^{+}$ synthesis via the salvage pathway which consumes ATP (Szabó, 2006). Furthermore, this process results in ribosylation and inactivation of glyceraldehyde-3-phosphate dehydrogenase (GAPDH), resulting in increased intermediates of glycolysis thus activating the proinflammatory transcription factor (Du et al., 2003). Several studies link inflammation and T2D and are associated with increase in CRP and IL-6 (Pradhan et al., 2001). Additional mechanisms for increased inflammation in $\mathrm{dbCM}$ include activation of NADPH oxidase, endoplasmic reticulum (ER) stress and oxidative stress mediated by Ras-related C3 botulinum toxin substrate 1 (RAC1) (Li et al., 2010).

\section{T CELL SENESCENCE}

Ageing-associated cellular senescence is also seen in the immune system, termed "immunosenescence", and is characterised by impaired vaccination responses, a greater susceptibility to infections and the development of age-related diseases (Fulop et al., 2017). Immunosenescence effects both the innate and adaptive immune system, changes to innate immunity are thought to reflect cellular dysfunction (Shaw et al., 2013), characterised by persistent systemic inflammation in the absence of infection.

The adaptive immune system is particularly sensitive to senescence, with both humoral and $\mathrm{T}$ cell immunity exhibiting many phenotypic and functional hallmarks of senescence, such as short telomeres, reduced cell proliferation and increased p16 expression (Frasca et al., 2017; Callender et al., 2018). Together with a rise in the number of terminally differentiated cells secreting a highly inflammatory SASP (Frasca et al,, 2017; Callender et al., 2018). However, much of the deterioration in the protective immune response has been attributed to defective $\mathrm{T}$ cell immunity (Nikolich-Zugich, 2005).

There is an ever-growing appreciation that senescent $\mathrm{T}$ cells also play a role in many chronic inflammatory and metabolic diseases (Shirakawa et al., 2016; Callender et al., 2018). Indeed, a recent paper highlighted the importance of immunosenescence in the pathogenesis of age-related disease. By selectively deleting Ercc1, a nuclease involved in DNA nucleotide excision repair, in haematopoietic cells, the authors created a mouse model of accelerating immune ageing. They were able to demonstrate that solid organs also showed increased senescence and damage, indicating that senescent, aged immune cells can promote systemic ageing (Yousefzadeh et al., 2021). T2D is a disease of ageing and a model of premature immunosenescence (Nikolich-Zugich, 2005). A loss of naïve $\mathrm{CD}^{+}$and $\mathrm{CD} 8^{+} \mathrm{T}$ cells along with a rise in late stage differentiated $\mathrm{T}$ cells has been reported in T2D (Giubilato et al., 2011; Lau et al., 2019). Furthermore, it has been demonstrated that the presence of senescent $\mathrm{T}$ cells can predict the development of hyperglycaemia in humans (Lee et al., 2019). However, both the innate and adaptive immune response in T2D show functional impairments that resemble those of ageing: poor control of infections and reduced vaccination responses together with elevated inflammatory activity (Lau et al., 2019).

Cell metabolism is a vital regulator of $\mathrm{T}$ cell fate and function, and the metabolic requirements of $\mathrm{T}$ cells change in meet the demands put upon them. However, senescent $\mathrm{T}$ cells exhibit mitochondrial dysfunction and consequently a reliance on glycolysis (Henson et al., 2014). Senescent $T$ cells strongly resemble diabetic $T$ cells in that they display impaired glucose uptake and increased fatty acid uptake but a decline in FAO (Lau et al., 2019). This abnormal glucose homeostasis observed during immunosenescence may be due to a disrupted balance between endosomal recycling and autophagy, specifically ATG9 (Henson et al., 2014). Indeed, ATG proteins have been shown to directly interact with membranes, transfer lipids between membranes and regulate lipid metabolism (Nishimura and Tooze, 2020). However, their role in altered lipid handle during T2D remains to be examined. Therefore, the alterations in the metabolism observed in senescent $\mathrm{T}$ cells may have the potential to drive metabolic disease.

\section{SENOLYTICS AND IMMUNOMODULATION}

Numerous reports have demonstrated that the removal of senescent cells delays age-related tissue dysfunction, increases 
health span and ameliorates disease (Baker et al., 2016). Furthermore, novel drugs termed senolytics, which kill senescent cells have been shown to help maintain homeostasis in aged or damaged tissues, and postpone many age-related pathologies (Kale et al., 2020). The inflammatory secretome produced by senescent cells recruits immune cells to eliminate then but senescent cells can also interact with immune cells to avoid elimination. The expression of HLA-E by senescent fibroblasts in culture and in the skin of older humans increases and interacts with NKG2A to inhibit NK and $\mathrm{CD}^{+}$cytotoxicity (Pereira et al., 2019).

Additionally, senescent $\mathrm{CD}^{+} \mathrm{T}$ cells preferentially express more inhibitory receptors, favouring expression of the inhibitory NKG2A rather than the activatory receptor, NKG2D (Pereira et al., 2019).

Metalloproteases secreted as part of the SASP cause the shedding of MICA and MICB, ligands for the activatory receptor NKG2D, preventing $\mathrm{NK}$ cells and $\mathrm{CD}^{+} \mathrm{T}$ cells from interacting adding an additional barrier in the removal of senescent cells (Muñoz et al., 2019). This defective immune mediated senescent cell clearance causes senescent cells to accumulate and enhance the proinflammatory environment. Therefore, modulation of the immune system may boost the effectiveness of senolytic therapies. This could be achieved by targeting the inflammatory secretome of senescent $\mathrm{T}$ cells. Inhibition of $\mathrm{p} 38 \mathrm{MAPK}$ in senescent $\mathrm{CD} 8^{+} \mathrm{T}$ cells reduces the production of a T cell SASP (Callender et al., 2018) as well as increasing their proliferation, telomerase activity, and mitochondrial biogenesis (Henson et al., 2014). Blocking the inhibitory HLA-E:NKG2A signaling axis was found to improve immune clearance of senescent cells when senescent fibroblasts were incubated with $\mathrm{NK}$ cells and late differentiated $\mathrm{CD}^{+} \mathrm{T}$ cells (Pereira et al., 2019). Altering the suppressive activity of regulatory T cells (Tregs) may also provide a useful strategy, as both aged mice and humans have an increased proportion of Tregs which suppress $\mathrm{T}$ effector cell function (Song et al., 2020). A study of supercentenarians older than 110 years were found to have elevated $\mathrm{CD} 4^{+}$cytotoxic $\mathrm{T}$ cells suggestive that an increased effector function boosts longevity (Hashimoto et al., 2019). Additionally, the selectivity and efficiency of cytotoxic $T$ cells could be reinstructed through the use of a modified $\mathrm{T}$ cell receptor or a chimeric antigen receptor (CAR) (June et al., 2018). The advantage of using CAR-T cells to target senescent cells is

\section{REFERENCES}

Aghajanian, H., Kimura, T., Rurik, J. G., Hancock, A. S., Leibowitz, M. S., Li, L., et al. (2019). Targeting Cardiac Fibrosis with Engineered T Cells. Nature 573, 430-433. doi:10.1038/s41586-019-1546-Z

Alvarez-Guardia, D., Palomer, X., Coll, T., Davidson, M. M., Chan, T. O., Feldman, A. M., et al. (2010). The P65 Subunit of NF-kappaB Binds to PGC-1alpha, Linking Inflammation and Metabolic Disturbances in Cardiac Cells. Cardiovasc. Res. 87, 449-458. doi: $10.1093 / \mathrm{cvr} / \mathrm{cvq} 080$

Amor, C., Feucht, J., Leibold, J., Ho, Y. J., Zhu, C., Alonso-Curbelo, D., et al. (2020). Senolytic CAR T Cells Reverse Senescence-Associated Pathologies. Nature 583, 127-132. doi:10.1038/s41586-020-2403-9

An, D., and Rodrigues, B. (2006). Role of Changes in Cardiac Metabolism in Development of Diabetic Cardiomyopathy. Am. J. Physiol. Heart Circ. Physiol. 291, H1489-H1506. doi:10.1152/ajpheart.00278.2006 that they are able to access deep into tissues where senescent cells reside (Kale et al., 2020). Indeed, a CAR-T engineered against fibroblast activation protein found in active cardiac fibroblasts and a driver of myocardial disease, was shown to alleviate cardiac fibrosis and reverse both systolic and diastolic cardiac function (Aghajanian et al., 2019). Senescence-specific surface antigens can also serve as targets for CAR-T cells, when the urokinase-type plasminogen activator receptor, induced during senescence was engineered into a CAR-T it was found to restore tissue homeostasis in mice with liver fibrosis (Amor et al., 2020). The potential of CAR-T cell therapy has yet to be fully realised.

\section{CONCLUSION}

A better understanding of immunosenescence in cardiomyopathy is needed to speed the development of novel therapeutic interventions. While several small-molecule drugs and senolytics have entered clinical trials to counter cellular senescence-associated ageing and cardiovascular disease, there remain many unanswered questions. We need a more thorough understanding of the heterogeneity of senescent cells and of the targets for potential immune cell intervention. In addition, we need to determine how immune cells interact with senescent cells in the T2D heart. Importantly, it is crucial to understand the mechanism by which senescent cells avoid immune clearance in order to develop strategies to boost the natural senolytic ability of immune cells.

\section{AUTHOR CONTRIBUTIONS}

SH and DA drafted the manuscript and prepared the figures.

\section{FUNDING}

DA Wellcome Trust (221604/Z/20/Z), British Heart Foundation Accelerator Award (AA/18/5/34222), Diabetes UK Grant (19/ 0005973), Barts Charity Grant (MRC 0215), SH Barts and the London Charity (MGU 0536), Diabetes UK (19/0006057).

Anderson, R., Lagnado, A., Maggiorani, D., Walaszczyk, A., Dookun, E., Chapman, J., et al. (2019). Length-independent Telomere Damage Drives post-mitotic Cardiomyocyte Senescence. EMBO J. 38, e100492. doi:10.15252/embj.2018100492

Anderson, R. J., Freedland, K. E., Clouse, R. E., and Lustman, P. J. (2001). The Prevalence of Comorbid Depression in Adults with Diabetes: a Meta-Analysis. Diabetes Care 24, 1069-1078. doi:10.2337/diacare.24.6.1069

Baker, D. J., Childs, B. G., Durik, M., Wijers, M. E., Sieben, C. J., Zhong, J., et al. (2016). Naturally Occurring p16(Ink4a)-Positive Cells Shorten Healthy Lifespan. Nature 530, 184-189. doi:10.1038/nature16932

Baker, R. G., Hayden, M. S., and Ghosh, S. (2011). NF- $\mathrm{B}$, Inflammation, and Metabolic Disease. Cell Metab. 13, 11-22. doi:10.1016/j.cmet.2010.12.008

Ball, A. J., and Levine, F. (2005). Telomere-independent Cellular Senescence in Human Fetal Cardiomyocytes. Aging Cell 4, 21-30. doi:10.1111/j.1474-9728.2004.00137.x

Barron, E., Bakhai, C., Kar, P., Weaver, A., Bradley, D., Ismail, H., et al. (2020). Associations of Type 1 and Type 2 Diabetes with COVID-19-Related Mortality in England: a Whole-Population Study. Lancet Diabetes Endocrinol. 8, 813-822. doi:10.1016/S2213-8587(20)30272-2 
Basisty, N., Kale, A., Jeon, O. H., Kuehnemann, C., Payne, T., Rao, C., et al. (2020). A Proteomic Atlas of Senescence-Associated Secretomes for Aging Biomarker Development. Plos Biol. 18, e3000599. doi:10.1371/journal.pbio.3000599

Beckman, J. A., Creager, M. A., and Libby, P. (2002). Diabetes and Atherosclerosis: Epidemiology, Pathophysiology, and Management. JAMA 287, 2570-2581. doi:10.1001/jama.287.19.2570

Bertoni, A. G., Tsai, A., Kasper, E. K., and Brancati, F. L. (2003). Diabetes and Idiopathic Cardiomyopathy: a Nationwide Case-Control Study. Diabetes Care 26, 2791-2795. doi:10.2337/diacare.26.10.2791

Blazer, S., Khankin, E., Segev, Y., Ofir, R., Yalon-Hacohen, M., Kra-Oz, Z., et al. (2002). High Glucose-Induced Replicative Senescence: point of No Return and Effect of Telomerase. Biochem. Biophys. Res. Commun. 296, 93-101. doi:10.1016/s0006-291x(02)00818-5

Brem, H., and Tomic-Canic, M. (2007). Cellular and Molecular Basis of Wound Healing in Diabetes. J. Clin. Invest. 117, 1219-1222. doi:10.1172/JCI32169

Callender, L. A., Carroll, E. C., Beal, R. W. J., Chambers, E. S., Nourshargh, S., Akbar, A. N., et al. (2018). Human CD8+ EMRA T Cells Display a SenescenceAssociated Secretory Phenotype Regulated by P38 MAPK. Aging Cell 17, e12675. doi:10.1111/acel.12675

Campisi, J., and d'Adda di Fagagna, F. (2007). Cellular Senescence: when Bad Things Happen to Good Cells. Nat. Rev. Mol. Cel. Biol. 8, 729-740. doi:10.1038/ nrm2233

Carey, V. J., Walters, E. E., Colditz, G. A., Solomon, C. G., Willett, W. C., Rosner, B. A., et al. (1997). Body Fat Distribution and Risk of Non-insulin-dependent Diabetes Mellitus in Women. The Nurse's Health Study. Am. J. Epidemiol. 145, 614-619. doi:10.1093/oxfordjournals.aje.a009158

Cerf, M. E. (2013). Beta Cell Dysfunction and Insulin Resistance. Front. Endocrinol. (Lausanne) 4, 37. doi:10.3389/fendo.2013.00037

Chabi, B., Ljubicic, V., Menzies, K. J., Huang, J. H., Saleem, A., and Hood, D. A. (2008). Mitochondrial Function and Apoptotic Susceptibility in Aging Skeletal Muscle. Aging Cell 7, 2-12. doi:10.1111/j.1474-9726.2007.00347.x

Chiao, Y. A., Kolwicz, S. C., Basisty, N., Gagnidze, A., Zhang, J., Gu, H., et al. (2016). Rapamycin Transiently Induces Mitochondrial Remodeling to Reprogram Energy Metabolism in Old Hearts. Aging (Albany NY) 8, 314-327. doi:10.18632/aging.100881

Childs, B. G., Baker, D. J., Kirkland, J. L., Campisi, J., and van Deursen, J. M. (2014). Senescence and Apoptosis: Dueling or Complementary Cell Fates. EMBO Rep. 15, 1139-1153. doi:10.15252/embr.201439245

Childs, B. G., Gluscevic, M., Baker, D. J., Laberge, R. M., Marquess, D., Dananberg, J., et al. (2017). Senescent Cells: an Emerging Target for Diseases of Ageing. Nat. Rev. Drug Discov. 16, 718-735. doi:10.1038/nrd.2017.116

Coppé, J. P., Patil, C. K., Rodier, F., Sun, Y., Muñoz, D. P., Goldstein, J., et al. (2008). Senescence-associated Secretory Phenotypes Reveal Cell-Nonautonomous Functions of Oncogenic RAS and the P53 Tumor Suppressor. Plos Biol. 6, 2853-2868. doi:10.1371/journal.pbio.0060301

Cramer, C., Freisinger, E., Jones, R. K., Slakey, D. P., Dupin, C. L., Newsome, E. R., et al. (2010). Persistent High Glucose Concentrations Alter the Regenerative Potential of Mesenchymal Stem Cells. Stem Cell Dev 19, 1875-1884. doi:10.1089/scd.2010.0009

Cui, S., Xue, L., Yang, F., Dai, S., Han, Z., Liu, K., et al. (2018). Postinfarction Hearts Are Protected by Premature Senescent Cardiomyocytes via GATA 4Dependent CCN 1 Secretion. J. Am. Heart Assoc. 7, e009111. doi:10.1161/ JAHA.118.009111

Czech, M. P. (2017). Insulin Action and Resistance in Obesity and Type 2 Diabetes. Nat. Med. 23, 804-814. doi:10.1038/nm.4350

Defronzo, R. A. (2009). Banting Lecture. From the Triumvirate to the Ominous Octet: a New Paradigm for the Treatment of Type 2 Diabetes Mellitus. Diabetes 58, 773-795. doi:10.2337/db09-9028

Demaria, M., Ohtani, N., Youssef, S. A., Rodier, F., Toussaint, W., Mitchell, J. R., et al. (2014). An Essential Role for Senescent Cells in Optimal Wound Healing through Secretion of PDGF-AA. Dev. Cel 31, 722-733. doi:10.1016/ j.devcel.2014.11.012

Dennis, J. M., Mateen, B. A., Sonabend, R., Thomas, N. J., Patel, K. A., Hattersley, A. T., et al. (2021). Type 2 Diabetes and COVID-19-Related Mortality in the Critical Care Setting: A National Cohort Study in England, March-July 2020. Dia Care 44, 50-57. doi:10.2337/dc20-1444

Diamant, M., Lamb, H. J., Groeneveld, Y., Endert, E. L., Smit, J. W., Bax, J. J., et al. (2003). Diastolic Dysfunction Is Associated with Altered Myocardial
Metabolism in Asymptomatic Normotensive Patients with Well-Controlled Type 2 Diabetes Mellitus. J. Am. Coll. Cardiol. 42, 328-335. doi:10.1016/s07351097(03)00625-9

Dookun, E., Passos, J., Arthur, H., and Richardson, G. (2020). Therapeutic Potential of Senolytics in Cardiovascular Disease. Cardiovascular Drugs and Therapy. Switzerland: Springer Nature.

Du, X., Matsumura, T., Edelstein, D., Rossetti, L., Zsengellér, Z., Szabó, C., et al. (2003). Inhibition of GAPDH Activity by poly(ADP-Ribose) Polymerase Activates Three Major Pathways of Hyperglycemic Damage in Endothelial Cells. J. Clin. Invest. 112, 1049-1057. doi:10.1172/JCI18127

Elzi, D. J., Lai, Y., Song, M., Hakala, K., Weintraub, S. T., and Shiio, Y. (2012). Plasminogen Activator Inhibitor 1-insulin-like Growth Factor Binding Protein 3 cascade Regulates Stress-Induced Senescence. Proc. Natl. Acad. Sci. U S A. 109, 12052-12057. doi:10.1073/pnas.1120437109

Emerging Risk Factors, C., Sarwar, N., Gao, P., Seshasai, S. R., Gobin, R., Kaptoge, S., et al. (2010). Diabetes Mellitus, Fasting Blood Glucose Concentration, and Risk of Vascular Disease: a Collaborative Meta-Analysis of 102 Prospective Studies. Lancet 375, 2215-2222. doi:10.1016/S0140-6736(10)60484-9

Fein, F. S. (1990). Diabetic Cardiomyopathy. Diabetes Care 13, 1169-1179. doi:10.2337/diacare.13.11.1169

Ford, J. H. (2010). Saturated Fatty Acid Metabolism Is Key Link between Cell Division, Cancer, and Senescence in Cellular and Whole Organism Aging. Age (Dordr) 32, 231-237. doi:10.1007/s11357-009-9128-x

Franceschi, C., and Campisi, J. (2014). Chronic Inflammation (Inflammaging) and its Potential Contribution to Age-Associated Diseases. J. Gerontol. A. Biol. Sci. Med. Sci. 69 (Suppl. 1), S4-S9. doi:10.1093/gerona/glu057

Frasca, D., Diaz, A., Romero, M., and Blomberg, B. B. (2017). Human Peripheral Late/exhausted Memory B Cells Express a Senescent-Associated Secretory Phenotype and Preferentially Utilize Metabolic Signaling Pathways. Exp. Gerontol. 87, 113-120. doi:10.1016/j.exger.2016.12.001

Frati, G., Schirone, L., Chimenti, I., Yee, D., Biondi-Zoccai, G., Volpe, M., et al. (2017). An Overview of the Inflammatory Signalling Mechanisms in the Myocardium Underlying the Development of Diabetic Cardiomyopathy. Cardiovasc. Res. 113, 378-388. doi:10.1093/cvr/cvx011

Fulop, T., Larbi, A., Dupuis, G., Le Page, A., Frost, E. H., Cohen, A. A., et al. (2017). Immunosenescence and Inflamm-Aging as Two Sides of the Same Coin: Friends or Foes. Front. Immunol. 8, 1960. doi:10.3389/fimmu.2017.01960

Fumagalli, M., Rossiello, F., Clerici, M., Barozzi, S., Cittaro, D., Kaplunov, J. M., et al. (2012). Telomeric DNA Damage Is Irreparable and Causes Persistent DNA-Damage-Response Activation. Nat. Cel. Biol. 14, 355-365. doi:10.1038/ ncb2466

Galadari, S., Rahman, A., Pallichankandy, S., Galadari, A., and Thayyullathil, F. (2013). Role of Ceramide in Diabetes Mellitus: Evidence and Mechanisms. Lipids Health Dis. 12, 98. doi:10.1186/1476-511X-12-98

Galicia-Garcia, U., Benito-Vicente, A., Jebari, S., Larrea-Sebal, A., Siddiqi, H., Uribe, K. B., et al. (2020). Pathophysiology of Type 2 Diabetes Mellitus. Int. J. Mol. Sci. 21, 6275. doi:10.3390/ijms 21176275

García, N., Zazueta, C., Martínez-Abundis, E., Pavón, N., and Chávez, E. (2009). Cyclosporin A Is Unable to Inhibit Carboxyatractyloside-Induced Permeability Transition in Aged Mitochondria. Comp. Biochem. Physiol. C Toxicol. Pharmacol. 149, 374-381. doi:10.1016/j.cbpc.2008.09.006

Giubilato, S., Liuzzo, G., Brugaletta, S., Pitocco, D., Graziani, F., Smaldone, C., et al. (2011). Expansion of CD4+CD28null T-Lymphocytes in Diabetic Patients: Exploring New Pathogenetic Mechanisms of Increased Cardiovascular Risk in Diabetes Mellitus. Eur. Heart J. 32, 1214-1226. doi:10.1093/eurheartj/ehq499

Gordon, J. W., Shaw, J. A., and Kirshenbaum, L. A. (2011). Multiple Facets of NFKb in the Heart: to Be or Not to NF-Kb. Circ. Res. 108, 1122-1132. doi:10.1161/ CIRCRESAHA.110.226928

Gorgoulis, V., Adams, P. D., Alimonti, A., Bennett, D. C., Bischof, O., Bishop, C., et al. (2019). Cellular Senescence: Defining a Path Forward. Cell 179, 813-827. doi:10.1016/j.cell.2019.10.005

Grarup, N., Sandholt, C. H., Hansen, T., and Pedersen, O. (2014). Genetic Susceptibility to Type 2 Diabetes and Obesity: from Genome-wide Association Studies to Rare Variants and beyond. Diabetologia 57, 1528-1541. doi:10.1007/s00125-014-3270-4

Hashimoto, K., Kouno, T., Ikawa, T., Hayatsu, N., Miyajima, Y., Yabukami, H., et al. (2019). Single-cell Transcriptomics Reveals Expansion of Cytotoxic CD4 
T Cells in Supercentenarians. Proc. Natl. Acad. Sci. U S A. 116, 24242-24251. doi:10.1073/pnas.1907883116

Helman, A., Klochendler, A., Azazmeh, N., Gabai, Y., Horwitz, E., Anzi, S., et al. (2016). p16(Ink4a)-induced Senescence of Pancreatic Beta Cells Enhances Insulin Secretion. Nat. Med. 22, 412-420. doi:10.1038/nm.4054

Henson, S. M., Lanna, A., Riddell, N. E., Franzese, O., Macaulay, R., Griffiths, S. J., et al. (2014). p38 Signaling Inhibits mTORC1-independent Autophagy in Senescent Human $\mathrm{CD}^{+} \mathrm{T}$ Cells. J. Clin. Invest. 124, 4004-4016. doi:10.1172/JCI75051

Hernandez-Segura, A., Nehme, J., and Demaria, M. (2018). Hallmarks of Cellular Senescence. Trends Cel. Biol. 28, 436-453. doi:10.1016/j.tcb.2018.02.001

Hex, N., Bartlett, C., Wright, D., Taylor, M., and Varley, D. (2012). Estimating the Current and Future Costs of Type 1 and Type 2 Diabetes in the UK, Including Direct Health Costs and Indirect Societal and Productivity Costs. Diabet Med. 29, 855-862. doi:10.1111/j.1464-5491.2012.03698.x

Hughes, M. J., McGettrick, H. M., and Sapey, E. (2020). Shared Mechanisms of Multimorbidity in COPD, Atherosclerosis and Type-2 Diabetes: the Neutrophil as a Potential Inflammatory Target. Eur. Respir. Rev. 29, 190102. doi:10.1183/ 16000617.0102-2019

Hyyti, O. M., Ledee, D., Ning, X. H., Ge, M., and Portman, M. A. (2010). Aging Impairs Myocardial Fatty Acid and Ketone Oxidation and Modifies Cardiac Functional and Metabolic Responses to Insulin in Mice. Am. J. Physiol. Heart Circ. Physiol. 299, H868-H875. doi:10.1152/ajpheart.00931.2009

June, C. H., O'Connor, R. S., Kawalekar, O. U., Ghassemi, S., and Milone, M. C. (2018). CAR T Cell Immunotherapy for Human Cancer. Science 359, 1361-1365. doi:10.1126/science.aar6711

Kale, A., Sharma, A., Stolzing, A., Desprez, P. Y., and Campisi, J. (2020). Role of Immune Cells in the Removal of Deleterious Senescent Cells. Immun. Ageing 17, 16. doi:10.1186/s12979-020-00187-9

Kannel, W. B., Hjortland, M., and Castelli, W. P. (1974). Role of Diabetes in Congestive Heart Failure: the Framingham Study. Am. J. Cardiol. 34, 29-34. doi:10.1016/0002-9149(74)90089-7

Kannel, W. B., and McGee, D. L. (1979). Diabetes and Cardiovascular Disease. The Framingham Study. JAMA 241, 2035-2038. doi:10.1001/jama.241.19.2035

Kannel, W. B., and McGee, D. L. (1979). Diabetes and Glucose Tolerance as Risk Factors for Cardiovascular Disease: the Framingham Study. Diabetes Care 2, 120-126. doi:10.2337/diacare.2.2.120

Kenny, H. C., and Abel, E. D. (2019). Heart Failure in Type 2 Diabetes Mellitus. Circ. Res. 124, 121-141. doi:10.1161/CIRCRESAHA.118.311371

Kim, K. S., Seu, Y. B., Baek, S. H., Kim, M. J., Kim, K. J., Kim, J. H., et al. (2007). Induction of Cellular Senescence by Insulin-like Growth Factor Binding Protein-5 through a P53-dependent Mechanism. Mol. Biol. Cel. 18, 4543-4552. doi:10.1091/mbc.e07-03-0280

Ko, H. J., Zhang, Z., Jung, D. Y., Jun, J. Y., Ma, Z., Jones, K. E., et al. (2009). Nutrient Stress Activates Inflammation and Reduces Glucose Metabolism by Suppressing AMP-Activated Protein Kinase in the Heart. Diabetes 58, 2536-2546. doi:10.2337/db08-1361

Ksiazek, K., Passos, J. F., Olijslagers, S., and von Zglinicki, T. (2008). Mitochondrial Dysfunction Is a Possible Cause of Accelerated Senescence of Mesothelial Cells Exposed to High Glucose. Biochem. Biophys. Res. Commun. 366, 793-799. doi:10.1016/j.bbrc.2007.12.021

Kuilman, T., and Peeper, D. S. (2009). Senescence-messaging Secretome: SMS-Ing Cellular Stress. Nat. Rev. Cancer 9, 81-94. doi:10.1038/nrc2560

Lau, E. Y. M., Carroll, E. C., Callender, L. A., Hood, G. A., Berryman, V., Pattrick, M., et al. (2019). Type 2 Diabetes Is Associated with the Accumulation of Senescent T Cells. Clin. Exp. Immunol. 197, 205-213. doi:10.1111/cei.13344

Lee, Y. H., Kim, S. R., Han, D. H., Yu, H. T., Han, Y. D., Kim, J. H., et al. (2019). Senescent T Cells Predict the Development of Hyperglycemia in Humans. Diabetes 68, 156-162. doi:10.2337/db17-1218

Lesnefsky, E. J., Chen, Q., and Hoppel, C. L. (2016). Mitochondrial Metabolism in Aging Heart. Circ. Res. 118, 1593-1611. doi:10.1161/ CIRCRESAHA.116.307505

Li, H., Zhou, C., Chen, D., Fang, N., Yao, Y., and Li, L. (2013). Failure to Protect against Myocardial Ischemia-Reperfusion Injury with Sevoflurane Postconditioning in Old Rats In Vivo. Acta Anaesthesiol. Scand. 57, 1024-1031. doi:10.1111/aas.12156

Li, J., Zhu, H., Shen, E., Wan, L., Arnold, J. M., and Peng, T. (2010). Deficiency of Rac1 Blocks NADPH Oxidase Activation, Inhibits Endoplasmic Reticulum
Stress, and Reduces Myocardial Remodeling in a Mouse Model of Type 1 Diabetes. Diabetes 59, 2033-2042. doi:10.2337/db09-1800

Liu, J., Huang, K., Cai, G. Y., Chen, X. M., Yang, J. R., Lin, L. R., et al. (2014). Receptor for Advanced Glycation End-Products Promotes Premature Senescence of Proximal Tubular Epithelial Cells via Activation of Endoplasmic Reticulum Stress-dependent P21 Signaling. Cell Signal 26, 110-121. doi:10.1016/j.cellsig.2013.10.002

Lopaschuk, G. D., Karwi, Q. G., Tian, R., Wende, A. R., and Abel, E. D. (2021) Cardiac Energy Metabolism in Heart Failure. Circ. Res. 128, 1487-1513. doi:10.1161/CIRCRESAHA.121.318241

López-Otín, C., Blasco, M. A., Partridge, L., Serrano, M., and Kroemer, G. (2013). The Hallmarks of Aging. Cell 153, 1194-1217. doi:10.1016/ j.cell.2013.05.039

Maeda, M., Hayashi, T., Mizuno, N., Hattori, Y., and Kuzuya, M. (2015). Intermittent High Glucose Implements Stress-Induced Senescence in Human Vascular Endothelial Cells: Role of Superoxide Production by NADPH Oxidase. PLoS One 10, e0123169. doi:10.1371/journal.pone.0123169

Maejima, Y., Adachi, S., Ito, H., Hirao, K., and Isobe, M. (2008). Induction of Premature Senescence in Cardiomyocytes by Doxorubicin as a Novel Mechanism of Myocardial Damage. Aging Cell 7, 125-136. doi:10.1111/ j.1474-9726.2007.00358.x

Marelli-Berg, F. M., and Aksentijevic, D. (2019). Immunometabolic Cross-Talk in the Inflamed Heart. Cell Stress 3, 240-266. doi:10.15698/cst2019.08.194

Mariappan, N., Elks, C. M., Sriramula, S., Guggilam, A., Liu, Z., Borkhsenious, O., et al. (2010). NF-kappaB-induced Oxidative Stress Contributes to Mitochondrial and Cardiac Dysfunction in Type II Diabetes. Cardiovasc. Res. 85, 473-483. doi:10.1093/cvr/cvp305

Minamino, T., and Komuro, I. (2007). Vascular Cell Senescence: Contribution to Atherosclerosis. Circ. Res. 100, 15-26. doi:10.1161/ 01.RES.0000256837.40544.4a

Minamino, T., Orimo, M., Shimizu, I., Kunieda, T., Yokoyama, M., Ito, T., et al. (2009). A Crucial Role for Adipose Tissue P53 in the Regulation of Insulin Resistance. Nat. Med. 15, 1082-1087. doi:10.1038/nm.2014

Miranda, J. J., Barrientos-Gutiérrez, T., Corvalan, C., Hyder, A. A., Lazo-Porras, M., Oni, T., et al. (2019). Understanding the Rise of Cardiometabolic Diseases in Low- and Middle-Income Countries. Nat. Med. 25, 1667-1679. doi:10.1038/ s41591-019-0644-7

Muñoz, D. P., Yannone, S. M., Daemen, A., Sun, Y., Vakar-Lopez, F., Kawahara, M., et al. (2019). Targetable Mechanisms Driving Immunoevasion of Persistent Senescent Cells Link Chemotherapy-Resistant Cancer to Aging. JCI Insight 5, e124716. doi:10.1172/jci.insight.124716

Muñoz-Espín, D., Cañamero, M., Maraver, A., Gómez-López, G., Contreras, J., Murillo-Cuesta, S., et al. (2013). Programmed Cell Senescence during Mammalian Embryonic Development. Cell. 155, 1104-1118. doi:10.1016/ j.cell.2013.10.019

Muñoz-Espín, D., and Serrano, M. (2014). Cellular Senescence: from Physiology to Pathology. Nat. Rev. Mol. Cel. Biol. 15, 482-496. doi:10.1038/nrm3823

Nelson, G., Wordsworth, J., Wang, C., Jurk, D., Lawless, C., Martin-Ruiz, C., et al. (2012). A Senescent Cell Bystander Effect: Senescence-Induced Senescence. Aging Cell 11, 345-349. doi:10.1111/j.1474-9726.2012.00795.x

Nikolich-Zugich, J. (2005). T Cell Aging: Naive but Not Young. J. Exp. Med. 201, 837-840. doi:10.1084/jem.20050341

Nishimura, T., and Tooze, S. A. (2020). Emerging Roles of ATG Proteins and Membrane Lipids in Autophagosome Formation. Cell Discov. 6, 32. doi:10.1038/s41421-020-0161-3

Ock, S., Lee, W. S., Ahn, J., Kim, H. M., Kang, H., Kim, H. S., et al. (2016). Deletion of IGF-1 Receptors in Cardiomyocytes Attenuates Cardiac Aging in Male Mice. Endocrinology 157, 336-345. doi:10.1210/en.2015-1709

Olivieri, F., Recchioni, R., Marcheselli, F., Abbatecola, A. M., Santini, G., Borghetti, G., et al. (2013). Cellular Senescence in Cardiovascular Diseases: Potential AgeRelated Mechanisms and Implications for Treatment. Curr. Pharm. Des. 19, 1710-1719. doi:10.2174/1381612811319090018

Palmer, A. K., Gustafson, B., Kirkland, J. L., and Smith, U. (2019). Cellular Senescence: at the Nexus between Ageing and Diabetes. Diabetologia 62, 1835-1841. doi:10.1007/s00125-019-4934-x

Palmer, A. K., Tchkonia, T., LeBrasseur, N. K., Chini, E. N., Xu, M., and Kirkland, J. L. (2015). Cellular Senescence in Type 2 Diabetes: A Therapeutic Opportunity. Diabetes 64, 2289-2298. doi:10.2337/db14-1820 
Palomer, X., Alvarez-Guardia, D., Rodríguez-Calvo, R., Coll, T., Laguna, J. C., Davidson, M. M., et al. (2009). TNF-alpha Reduces PGC-1alpha Expression through NF-kappaB and P38 MAPK Leading to Increased Glucose Oxidation in a Human Cardiac Cell Model. Cardiovasc. Res. 81, 703-712. doi:10.1093/cvr/ cvn 327

Panel, M., Ghaleh, B., and Morin, D. (2018). Mitochondria and Aging: A Role for the Mitochondrial Transition Pore. Aging Cell 17, e12793. doi:10.1111/ acel. 12793

Pearson, T., Wattis, J. A., King, J. R., MacDonald, I. A., and Mazzatti, D. J. (2016). The Effects of Insulin Resistance on Individual Tissues: An Application of a Mathematical Model of Metabolism in Humans. Bull. Math. Biol. 78, 1189-1217. doi:10.1007/s11538-016-0181-1

Pereira, B. I., Devine, O. P., Vukmanovic-Stejic, M., Chambers, E. S., Subramanian, P., Patel, N., et al. (2019). Senescent Cells Evade Immune Clearance via HLA-EMediated NK and CD8+ T Cell Inhibition. Nat. Commun. 10, 2387. doi:10.1038/s41467-019-10335-5

Pradhan, A. D., Manson, J. E., Rifai, N., Buring, J. E., and Ridker, P. M. (2001). C-reactive Protein, Interleukin 6, and Risk of Developing Type 2 Diabetes Mellitus. JAMA 286, 327-334. doi:10.1001/jama.286.3.327

Schwartz, S. S., Epstein, S., Corkey, B. E., Grant, S. F., Gavin, J. R., 3rd, and Aguilar, R. B. (2016). The Time Is Right for a New Classification System for Diabetes: Rationale and Implications of the $\beta$-Cell-Centric Classification Schema. Diabetes Care 39, 179-186. doi:10.2337/dc15-1585

Shah, A. D., Langenberg, C., Rapsomaniki, E., Denaxas, S., Pujades-Rodriguez, M., Gale, C. P., et al. (2015). Type 2 Diabetes and Incidence of Cardiovascular Diseases: a Cohort Study in 1.9 Million People. Lancet Diabetes Endocrinol. 3, 105-113. doi:10.1016/S2213-8587(14)70219-0

Shah, M. S., and Brownlee, M. (2016). Molecular and Cellular Mechanisms of Cardiovascular Disorders in Diabetes. Circ. Res. 118, 1808-1829. doi:10.1161/ CIRCRESAHA.116.306923

Shakeri, H., Lemmens, K., Gevaert, A. B., De Meyer, G. R. Y., and Segers, V. F. M. (2018). Cellular Senescence Links Aging and Diabetes in Cardiovascular Disease. Am. J. Physiol. Heart Circ. Physiol. 315, H448-H462. doi:10.1152/ ajpheart.00287.2018

Shaw, A. C., Goldstein, D. R., and Montgomery, R. R. (2013). Age-dependent Dysregulation of Innate Immunity. Nat. Rev. Immunol. 13, 875-887. doi:10.1038/nri3547

Shay, J. W., and Wright, W. E. (2019). Telomeres and Telomerase: Three Decades of Progress. Nat. Rev. Genet. 20, 299-309. doi:10.1038/s41576-019-0099-1

Shimizu, I., and Minamino, T. (2019). Cellular Senescence in Cardiac Diseases. J. Cardiol. 74, 313-319. doi:10.1016/j.jjcc.2019.05.002

Shirakawa, K., Yan, X., Shinmura, K., Endo, J., Kataoka, M., Katsumata, Y., et al. (2016). Obesity Accelerates $\mathrm{T}$ Cell Senescence in Murine Visceral Adipose Tissue. J. Clin. Invest. 126, 4626-4639. doi:10.1172/ JCI88606

Sinha, R., Dufour, S., Petersen, K. F., LeBon, V., Enoksson, S., Ma, Y. Z., et al. (2002). Assessment of Skeletal Muscle Triglyceride Content by (1)H Nuclear Magnetic Resonance Spectroscopy in Lean and Obese Adolescents: Relationships to Insulin Sensitivity, Total Body Fat, and central Adiposity. Diabetes 51, 1022-1027. doi:10.2337/diabetes.51.4.1022

Sone, H., and Kagawa, Y. (2005). Pancreatic Beta Cell Senescence Contributes to the Pathogenesis of Type 2 Diabetes in High-Fat Diet-Induced Diabetic Mice. Diabetologia 48, 58-67. doi:10.1007/s00125-004-1605-2

Song, P., An, J., and Zou, M. H. (2020). Immune Clearance of Senescent Cells to Combat Ageing and Chronic Diseases. Cells 9, 671. doi:10.3390/ cells 9030671

Soto-Gamez, A., Quax, W. J., and Demaria, M. (2019). Regulation of Survival Networks in Senescent Cells: From Mechanisms to Interventions. J. Mol. Biol. 431, 2629-2643. doi:10.1016/j.jmb.2019.05.036

Storer, M., Mas, A., Robert-Moreno, A., Pecoraro, M., Ortells, M. C., Di Giacomo, V., et al. (2013). Senescence Is a Developmental Mechanism that Contributes to Embryonic Growth and Patterning. Cell 155, 1119-1130. doi:10.1016/ j.cell.2013.10.041

Stout, M. B., Tchkonia, T., Pirtskhalava, T., Palmer, A. K., List, E. O., Berryman, D. E., et al. (2014). Growth Hormone Action Predicts Age-Related white Adipose Tissue Dysfunction and Senescent Cell burden in Mice. Aging (Albany NY) 6, 575-586. doi:10.18632/aging.10068
Szabó, C. (2006). Poly(ADP-ribose) Polymerase Activation by Reactive Nitrogen Species-Rrelevance for the Pathogenesis of Inflammation. Nitric Oxide 14, 169-179. doi:10.1016/j.niox.2005.06.008

Tan, Y., Zhang, Z., Zheng, C., Wintergerst, K. A., Keller, B. B., and Cai, L. (2020). Mechanisms of Diabetic Cardiomyopathy and Potential Therapeutic Strategies: Preclinical and Clinical Evidence. Nat. Rev. Cardiol. 17, 585-607. doi:10.1038/ s41569-020-0339-2

Tang, X., Li, P. H., and Chen, H. Z. (2020). Cardiomyocyte Senescence and Cellular Communications within Myocardial Microenvironments. Front. Endocrinol. (Lausanne) 11, 280. doi:10.3389/fendo.2020.00280

Tavana, O., Puebla-Osorio, N., Sang, M., and Zhu, C. (2010). Absence of P53dependent Apoptosis Combined with Nonhomologous End-Joining Deficiency Leads to a Severe Diabetic Phenotype in Mice. Diabetes 59, 135-142. doi:10.2337/db09-0792

Tchkonia, T., Morbeck, D. E., Von Zglinicki, T., Van Deursen, J., Lustgarten, J., Scrable, H., et al. (2010). Fat Tissue, Aging, and Cellular Senescence. Aging Cell 9, 667-684. doi:10.1111/j.1474-9726.2010.00608.x

Tchkonia, T., Zhu, Y., van Deursen, J., Campisi, J., and Kirkland, J. L. (2013). Cellular Senescence and the Senescent Secretory Phenotype: Therapeutic Opportunities. J. Clin. Invest. 123, 966-972. doi:10.1172/ JCI64098

Thomas, C. M., Yong, Q. C., Rosa, R. M., Seqqat, R., Gopal, S., Casarini, D. E., et al. (2014). Cardiac-specific Suppression of NF-Kb Signaling Prevents Diabetic Cardiomyopathy via Inhibition of the Renin-Angiotensin System. Am. J. Physiol. Heart Circ. Physiol. 307, H1036-H1045. doi:10.1152/ajpheart.00340.2014

Thompson, P. J., Shah, A., Ntranos, V., Van Gool, F., Atkinson, M., and Bhushan, A. (2019). Targeted Elimination of Senescent Beta Cells Prevents Type 1 Diabetes. Cel. Metab. 29, 1045-e10. doi:10.1016/j.cmet.2019.01.021

Tran, D., Bergholz, J., Zhang, H., He, H., Wang, Y., Zhang, Y., et al. (2014). Insulinlike Growth Factor-1 Regulates the SIRT1-P53 Pathway in Cellular Senescence. Aging Cell 13, 669-678. doi:10.1111/acel.12219

Uchida, T., Nakamura, T., Hashimoto, N., Matsuda, T., Kotani, K., Sakaue, H., et al. (2005). Deletion of Cdknlb Ameliorates Hyperglycemia by Maintaining Compensatory Hyperinsulinemia in Diabetic Mice. Nat. Med. 11, 175-182. doi: $10.1038 / \mathrm{nm} 1187$

Westhoff, J. H., Hilgers, K. F., Steinbach, M. P., Hartner, A., Klanke, B., Amann, K., et al. (2008). Hypertension Induces Somatic Cellular Senescence in Rats and Humans by Induction of Cell Cycle Inhibitor p16INK4a. Hypertension 52, 123-129. doi:10.1161/HYPERTENSIONAHA.107.099432

World Health Organisation (2021). Diabetes. Geneva: World Health Organisation. Williams, G. C. (1957). Pleiotropy, Natural Selection, and the Evolution of Senescence. Evolution 11, 398-411. doi:10.1111/j.15585646.1957.tb02911.x

Wilson, P. W. (2001). Diabetes Mellitus and Coronary Heart Disease. Endocrinol. Metab. Clin. North. Am. 30, 857-881. doi:10.1016/s08898529(05)70219-x

Wong, N. D., Zhao, Y., Patel, R., Patao, C., Malik, S., Bertoni, A. G., et al. (2016). Cardiovascular Risk Factor Targets and Cardiovascular Disease Event Risk in Diabetes: A Pooling Project of the Atherosclerosis Risk in Communities Study, Multi-Ethnic Study of Atherosclerosis, and Jackson Heart Study. Diabetes Care 39, 668-676. doi:10.2337/dc15-2439

Yang, G., Badeanlou, L., Bielawski, J., Roberts, A. J., Hannun, Y. A., and Samad, F. (2009). Central Role of Ceramide Biosynthesis in Body Weight Regulation, Energy Metabolism, and the Metabolic Syndrome. Am. J. Physiol. Endocrinol. Metab. 297, E211-E224. doi:10.1152/ajpendo.91014.2008

Yokoi, T., Fukuo, K., Yasuda, O., Hotta, M., Miyazaki, J., Takemura, Y., et al. (2006). Apoptosis Signal-Regulating Kinase 1 Mediates Cellular Senescence Induced by High Glucose in Endothelial Cells. Diabetes 55, 1660-1665. doi:10.2337/db05-1607

Yousefzadeh, M. J., Flores, R. R., Zhu, Y., Schmiechen, Z. C., Brooks, R. W., Trussoni, C. E., et al. (2021). An Aged Immune System Drives Senescence and Ageing of Solid Organs. Nature 594, 100. doi:10.1038/s41586-02103547-7

Zhang, D., Hu, X., Li, J., Liu, J., Baks-Te Bulte, L., Wiersma, M., et al. (2019). DNA Damage-Induced PARP1 Activation Confers Cardiomyocyte Dysfunction through NAD+ Depletion in Experimental Atrial Fibrillation. Nat. Commun. 10, 1307. doi:10.1038/s41467-019-09014-2 
Zhu, J., Rebecchi, M. J., Glass, P. S., Brink, P. R., and Liu, L. (2011). Cardioprotection of the Aged Rat Heart by GSK-3beta Inhibitor Is Attenuated: Age-Related Changes in Mitochondrial Permeability Transition Pore Modulation. Am. J. Physiol. Heart Circ. Physiol. 300, H922-H930. doi:10.1152/ajpheart.00860.2010

Zhu, Y., Armstrong, J. L., Tchkonia, T., and Kirkland, J. L. (2014). Cellular Senescence and the Senescent Secretory Phenotype in Age-Related Chronic Diseases. Curr. Opin. Clin. Nutr. Metab. Care 17, 324-328. doi:10.1097/ MCO.0000000000000065

Zhu, Y., Tchkonia, T., Pirtskhalava, T., Gower, A. C., Ding, H., Giorgadze, N., et al. (2015). The Achille's Heel of Senescent Cells: from Transcriptome to Senolytic Drugs. Aging Cell 14, 644-658. doi:10.1111/acel.12344

Zuellig, R. A., Hornemann, T., Othman, A., Hehl, A. B., Bode, H., Güntert, T., et al. (2014). Deoxysphingolipids, Novel Biomarkers for Type 2 Diabetes, Are Cytotoxic for Insulin-Producing Cells. Diabetes 63, 1326-1339. doi:10.2337/ db13-1042
Conflict of Interest: The authors declare that the research was conducted in the absence of any commercial or financial relationships that could be construed as a potential conflict of interest.

Publisher's Note: All claims expressed in this article are solely those of the authors and do not necessarily represent those of their affiliated organizations, or those of the publisher, the editors and the reviewers. Any product that may be evaluated in this article, or claim that may be made by its manufacturer, is not guaranteed or endorsed by the publisher.

Copyright (c) 2021 Henson and Aksentijevic. This is an open-access article distributed under the terms of the Creative Commons Attribution License (CC BY). The use, distribution or reproduction in other forums is permitted, provided the original author(s) and the copyright owner(s) are credited and that the original publication in this journal is cited, in accordance with accepted academic practice. No use, distribution or reproduction is permitted which does not comply with these terms. 